\title{
A Clinical Study of AWT Measurement and Polynomial Regression Model Analysis in Critically III patients: A Retrospective Study
}

\section{Hao Tang}

Third Military Medical University Daping Hospital and Research Institute of Surgery: Army Medical Center of PLA

\section{Dongchu Zhao}

Army Medical University

\section{Chuan Zhang}

Army Medical University

\section{Xiaoying Huang}

Third Military Medical University Daping Hospital and Research Institute of Surgery: Army Medical Center of PLA

\section{Dong Liu}

Third Military Medical University Daping Hospital and Research Institute of Surgery: Army Medical Center of PLA

\section{Yang Li}

Third Military Medical University Daping Hospital and Research Institute of Surgery: Army Medical Center of PLA

\section{Yaoli Wang}

Third Military Medical University Daping Hospital and Research Institute of Surgery: Army Medical Center of PLA

\section{Dongpo Jiang}

Third Military Medical University Daping Hospital and Research Institute of Surgery: Army Medical Center of PLA

\section{Zhengguo Wang}

Third Military Medical University Daping Hospital and Research Institute of Surgery: Army Medical Center of PLA

\section{Huaping Liang}

Third Military Medical University Daping Hospital and Research Institute of Surgery: Army Medical Center of PLA

lianyang zhang ( $\nabla$ dpzhangly@163.com )

Army Medical University https://orcid.org/0000-0002-4882-7280 
Research article

Keywords: intra-abdominal hypertension, abdominal wall tension, intravesical pressure, polynomial regression, prognosis

Posted Date: June 7th, 2021

DOI: https://doi.org/10.21203/rs.3.rs-571122/v1

License: () (i) This work is licensed under a Creative Commons Attribution 4.0 International License. Read Full License 


\section{Abstract}

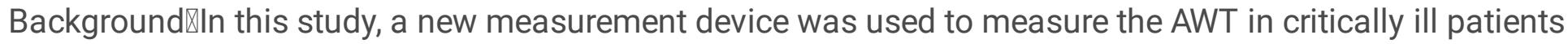
and a polynomial regression model was applied to analyze the correlation between intra-abdominal hypertension (IAH) and AWT in critically ill patients.

Methods: A retrospective analysis was conducted in critically ill patients who were admitted to the Department of Critical Care Medicine of Daping Hospital of Army Medical University from March 13, 2019, to May 23, 2020. According to the intravesical pressure (IVP) on the first day of ICU admission and death within 28 days, the patients were divided into the IAH group (IVP $\geq 12 \mathrm{mmHg}$ ), the non-IAH group, the survival group and the nonsurvival group. The demographic and clinical data, prognostic indicators, AWT and IVP on days 1-7 after entering the ICU, IAH risk factors, and 28-day death risk factors were collected.

Results: The AWT on the $1^{\text {st }}$ and mean $7^{\text {th }}$ day of the IAH group was $(2.89 \pm 0.32) \mathrm{N} / \mathrm{mm}$ and $(2.82 \pm 0.46)$ $\mathrm{N} / \mathrm{mm}$, respectively, which was higher than that of the non-IAH group [ $(2.45 \pm 0.29) \mathrm{N} / \mathrm{mm},(2.43 \pm 0.39)$ $\mathrm{N} / \mathrm{mm}], \mathrm{p} \otimes 0.001$. The average IVP on the $1^{\text {st }}$ and mean $7^{\text {th }}$ day of all patients were $12.78(6.14,18.99)$ and $11.49(6.66,19.43) \mathrm{mmHg}$, and the AWT on the $1^{\text {st }}$ and mean $7^{\text {th }}$ days were $(2.75 \pm 0.38)$ and $(2.75 \pm 0.47)$ $\mathrm{N} / \mathrm{mm}$, respectively, with significant differences $(\mathrm{p}<0.0001)$. The polynomial regression models showed that the average AWT and IVP on the $1^{\text {st }}$ and mean $7^{\text {th }}$ were AWT day $1=-2.450 \times 10^{-3}, I V P^{2}+9.695 \times 10^{-2}$

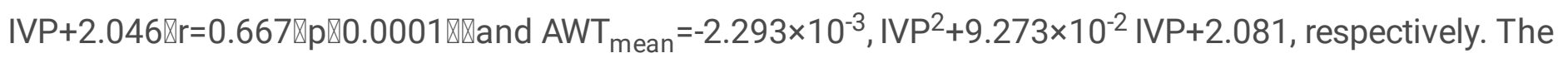
logistic regression analysis showed that $A W T_{\text {day } 1} 2.73-2.97 \mathrm{~N} / \mathrm{mm}$ increased the patient's 28-day mortality risk (OR: 6.834; 95\%: 1.105-42.266, $\mathrm{p}=0.010$ ).

Conclusion: There is a nonlinear correlation between AWT and IVP in critically ill patients, and a high AWT may indicate poor prognosis.

Trial registration囚ChiCTR囚ChiCTR1900020562. Registered 8 January 2019囚 http://www.chictr.org.cn/showproj.aspx?proj=34441

\section{Background}

Intra-abdominal hypertension (IAH) and abdominal compartment syndrome (ACS) have high morbidity and mortality among hospitalized patients, and they have involved nutrition, obstetrics and gynecology, breathing, severe illness, abdomen and abdominal wall surgery and many other disciplines[1-4].

Since the establishment of the World Society of the Abdominal Compartment Syndrome (WSACS) in 2004, the occurrence, influence, treatment and prevention of IAH and ACS have been widely considered and recognized by medical workers $[1-3,5-6]$.

Based on previous knowledge, in 2014, Malbrain et al. further proposed the definition of abdominal compliance (AC), which is considered an important parameter for neglected critically ill patients[7]. Abdominal wall tension (AWT) plays a decisive role in AC due to the anatomical structure of the abdomen. With the technological innovation of open abdomen $(\mathrm{OA})$ and the understanding of abdominal wall 
anatomy, the assessment of AWT is particularly important to helping us understand the relationship between abdominal volume (AV), IAP and AC[8-9].

In the United States, there are approximately 350,000 hernia repair surgeries each year, making them one of the most common surgical procedures. Various tension-free hernia repairs and abdominal wall separation techniques may have risks of postoperative pain, infection and recurrence[4, 10-12]. Important factors that cause these problems include IAH, basic characteristics of the abdominal wall and changes in tension caused by surgery. Therefore, the quantitative measurement of AWT is particularly important[4, 11]. AWT not only can reflect the pressure of the abdominal cavity but also is related to intra-abdominal diseases such as peritonitis[13-14]. Considering the complexity of the abdominal wall structure and its possible nonlinear relationship with IVP, we improved the linear regression model and used a new mechanism to fit the data. We hope that our research will help us improve our understanding of the functional characteristics of the abdominal wall and provide new ideas to help diagnose and treat AWT-related diseases. In this study, a new measurement device was used to measure the AWT in critically ill patients and a polynomial regression model was applied to analyze the correlation between intra-abdominal hypertension (IAH) and AWT in critically ill patients and to provides new ideas for the diagnosis and treatment of critically ill patients with IAH.

\section{Methods}

This retrospective study included hospitalized patients in the intensive care unit (ICU) of Daping Hospital of the Army Medical University from March 13, 2019, to May 23, 2020. This trial was approved by our institution review board.

\subsection{Selection criteria}

Inclusion criteria: (1) critically ill patients admitted to the ICU; (2) hospitalization time $\geq 7$ days; (3) age $\geq 18$ years; (4)abdominal hypertension patients with $\geq 2$ high risk factors, where the high risk factors for abdominal hypertension included mechanical ventilation, abdominal surgery, severe trauma, obesity (BMI $\geq 30$ ), gastroparesis (retention in the stomach $>500 \mathrm{ml}$ ), intestinal obstruction (slow intestinal peristalsis confirmed by imaging), ascites, liver insufficiency combined with ascites, liver cirrhosis with ascites, other abdominal conditions (peritonitis, abscess), ascites, acidosis (PH囚7.2), hypothermia (body temperature $\varangle 33^{\circ} \mathrm{C}$ ), APACHE II score $\geq 24$, SOFA score $\geq 2$, high fluid resuscitation volume (24 hour intake > $5 \mathrm{~L}$ ), coagulation disorders (platelet count $<55 \times 10^{9} / \mathrm{L}$ or partially activated prothrombin time increased by 2 times or prothrombin time $<50 \%$ or international standardized ratio $>1.5$ ), sepsis (defined according to the 2013 International Sepsis Guidelines), shock or hypotension (systolic blood pressure $<90 \mathrm{mmHg}$ or lower than the average level by more than $40 \mathrm{mmHg}$ ); and (5) patients providing informed consent.

Exclusion criteria: (1) abdominal wall tension or intravesical pressure measurement not detected; (2) patients with large abdominal wall defects or scars or particularly developed abdominal muscles, e.g., athletes may affect the AWT measurement results; (3) patients with bladder rupture, urethral rupture, or no 
urinary catheter, etc., affecting the IVP measurement; (4) patients with mental and psychological disorders; and (5) patients with missing medical records.

\subsection{Research methods \\ 2.2.1 AWT measurement}

\subsubsection{AWT measuring equipment}

A noninvasive multipoint abdominal wall tension measurement device (Chinese patent No. ZL 201510799207.4) was used. The device consists of a power supply, high-precision resistance strain pressure sensor (JHBM-H3 pressure sensor, Bengbu Sensor System Engineering Co. Ltd., China.), instrumentation amplifier (ADI) semiconductor,AD623 instrumentation amplifier, spring self-reset displacement sensor (KTR-A self-reset linear displacement sensor, Taizhou Quantum Electronic Technology Wire Co., Ltd., China), data information processing module (Italy STMicroelectronics. STM32 microcontroller), data display module (OLED0.96), and data storage module (U disk) (Fig. 1).

\subsubsection{AWT working principle}

Power supply: The AWT measuring equipment has a power charging function and uses electromagnetic compatibility and other related designs to supply power to the sensors and MCU.

Pressure measurement: The high-precision resistance strain pressure sensor is located at the front end of the spring self-resetting displacement sensor. The front end of the high-precision resistance strain pressure sensor is forced to obtain a smaller signal voltage, which is amplified by the instrument amplifier module AD623 and processed by the MCU after obtaining the accurate pressure value. The measuring range is 0 $100 \mathrm{~N}$, and the accuracy is $0.1 \% \mathrm{FS}$.

Displacement measurement: According to the displacement change of the spring self-resetting displacement sensor, the voltage value is obtained. After filtering and data processing, a high-precision displacement distance is obtained. The linear accuracy is $0.03 \% \mathrm{FS}$, and the stroke is $45 \mathrm{~mm}$.

Data information processing module: The STM32 single-chip microcomputer samples 100 values in $1 \mathrm{~s}$ with a sampling interval of $0.01 \mathrm{~s}$, and the collected sensor data are processed through data to obtain accurate values.

Data storage module: The pressure value, displacement value, and calculated muscle tension data are recorded and stored in the $\mathrm{U}$ disk in real time, and the file is in ".csv" format.

\subsubsection{AWT measurement method and result analysis}

Patients were in a quiet state and placed in supine position, and coverings such as abdominal clothing and accessories were removed. For mechanically ventilated patients, the ventilator parameters ( $P E E P=0$ $\mathrm{mmHg}$ ) were adjusted. Nine points on the abdominal wall were selected as the measurement points, as shown in Fig. 2. After turning on the device switch, the AWT measuring device was placed vertically and 
gently on the surface of the abdominal wall measuring point, and the displacement sensor was pressed at the end of the patient's expiration to the maximum displacement distance $(100 \mathrm{~mm})$. The device recorded the measured data at a frequency of $100 \mathrm{~Hz}$, and the same method was applied to press each point repeatedly approximately 20 times with a rate of $2-3 \mathrm{~s}$ each time. The measurement was completed after turning off the device.

MATLAB 2018a mathematical software from MathWorks, USA, was used for data analysis. The AWT data of each measurement point are presented as a pressure/displacement ratio curve, where the $X$-axis is time and the $\mathrm{Y}$-axis is the pressure/displacement ratio. Three curves with uniform and stable waveforms were selected, the average value of the maximum $Y$ values of the three curves was used as the final AWT result of each measurement point, and the average value of 9 points on the abdominal wall was used as the total AWT value. Figure 2 shows the location of 9 points on the abdominal wall.

\subsubsection{Measurement method of intravesical pressure(IVP)}

The IVP measurement method was applied based on the standard method developed by the WSACS 2013 guidelines[3]. Malbrain's modified sterile IVP measuring device was used to connect to the patient's urinary tube. Patients were lying flat and relaxed, and the parameters of the ventilator were adjusted (PEEP $=0$ $\mathrm{mmHg}$ ). After emptying the urine bag, $20 \mathrm{ml}$ of normal saline was injected, the 0 scale line of the device and the level of the mid-axillary line of the patient were measured, and the end-tidal reading value was taken as the measurement result and converted to $\mathrm{mmHg}$. Measurements were conducted twice, and the average value was taken as the final result.

\subsubsection{Research process}

All of the included patients were divided into an abdominal hypertension group and a nonperitoneal hypertension group according to their IVP value on the first day after entering the ICU. Abdominal hypertension was defined as IVP $\geq 12 \mathrm{mmHg}[3]$. Death within 28 days was used to define nonsurvival versus survival.

The basic data and clinical data (age, number of male patients, reason for admission, height and body mass index, APACHE II score, SOFA score, trauma patient ISS score, procalcitonin, C-reactive protein, lactic acid, sepsis diagnosis on the first day in ICU), IVP and AWT at 7 days after admission, IAH risk factors (risk factors related to decreased abdominal wall tension, increased intestinal cavity content, increased abdominal cavity content, or capillary leakage or fluid resuscitation), 28-day death risk factors (age $>65$ years, sepsis, laparotomy, intestinal obstruction, $\mathrm{PH}<7.2$, coagulation disorder, blood transfusion $>10 \mathrm{u} /$ day, injury control surgery, and IAH), and prognosis (death within 28 days and 90 days, ICU and total length of hospital stay) were collected(Fig. 3).

\subsubsection{Establishment of polynomial regression model of AWT and IVP}

IVP was divided into 5 pressure ranges according to an interval of $5 \mathrm{mmHg}$, and clustering was performed to obtain the cluster center. Polynomial regression and quadratic functions were used for fitting. MATLAB 
2018a mathematical software from MathWorks, USA, was used for data analysis.

\subsubsection{Statistical analysis}

Normally distributed measurement data were described using the mean and standard deviation (mean \pm std), differences between groups were compared by a T test, nonnormally distributed measurement data were described by the median $(25,75)$, and comparisons between groups were performed using a rank-sum test. The measurement data described the utilization rate (\%), the difference between groups was compared using a chi-squared test, and the linear statistical relationship between AWT and IVP was analyzed by Spearman's correlation. $\mathrm{P}<0.05$ was considered significant. A logistic regression analysis was used for 28day mortality risk factors.

\section{Results}

\subsection{Basic datalclinical data and prognostic indicators of patients in the IAH and non-IAH groups}

A total of 100 patients (55 males, $55 \%$ ) were enrolled, with an average age of $45.59 \pm 11.4$ years. Thirty patients (30\%) were admitted to the hospital for medical reasons, 43 patients $(43 \%)$ were admitted to the hospital for surgical reasons, and 27 patients $(27 \%)$ were admitted to the hospital for trauma. There were 50 patients ( 29 males, $58 \%$ ) in the IAH group, with an average age of $45.28 \pm 12.27$ years, and 50 patients (26 males, $52 \%$ ) in the non-IAH group, with an average age of $45.90 \pm 10.58$ years. In the IAH group, 10 patients $(20 \%)$ were admitted to the hospital for medical reasons, 20 patients $₫ 40 \% \bigotimes$ were admitted to the hospital for surgical reasons, and 20 patients $₫ 40 \% \otimes$ were admitted to the hospital for trauma; in the non-IAH group, 20 patients $₫ 40 \% \bigotimes$ were admitted to the hospital for medical reasons, 23 patients $₫ 46 \% \bigotimes$ were admitted to the hospital for surgical reasons, and $7 \otimes 14 \% \bigotimes$ patients were admitted to the hospital for trauma $(p=$ 0.007). Medical patients included those with pancreatitis, heart failure, severe pneumonia, etc.; surgical patients included those with intestinal perforation, cholecystitis, appendicitis, thyroid masses, etc.; and trauma patients included those with limb fractures, blood pneumothorax, head trauma, etc.

The procalcitonin concentration was $7.089(4.07,8.74) \mathrm{ng} / \mathrm{ml}$ in the IAH group, and the average IVP on the first and seventh days after entering the ICU was $18.99(17.52,20.77) \mathrm{mmHg}$ and $6.14(3.48,8.70) \mathrm{mmHg}$, respectively, which were higher than those in the non-IAH group $[4.79(2.97,5.43) \mathrm{ng} / \mathrm{ml}$, the average IVP: $19.43(16.87,22.25) \mathrm{mmHg}$ and $6.66(2.74,9.08) \mathrm{mmHg}$ on the $1 \mathrm{st}$ and mean 7 th days after entering the ICU], with significant differences ( $p<0.001)$. The average AWT of the IAH group on the 1 st and mean 7 th days was $2.89 \pm 0.32 \mathrm{~N} / \mathrm{mm}$ and $2.82 \pm 0.46 \mathrm{~N} / \mathrm{mm}$, respectively, which was higher than those of the nonIAH group $(2.45 \pm 0.29 \mathrm{~N} / \mathrm{mm}, 2.43 \pm 0.39 \mathrm{~N} / \mathrm{mm})$, with significant differences $(p<0.001)$.

In the IAH group, 18 patients died within 28 days(36\%), 20 patients died within 90 days (40\%), the ICU hospital stay was $7.48 \pm 3.88$ days, and the total hospital stay was $15.35 \pm 5.26$ days, which were higher than those of the non-IAH group (8 patients died within 28 days, 9 patients died within 90 days, the ICU 
hospital stay was $6.01 \pm 3.14$ days, and the total hospital stay was $13.10 \pm 4.24$ days), with significant differences $(P<0.05)$. There was no significant difference in the other indicators (Table 1$)$. 
Table 1

Basic and clinical data,prognostic indicators of patients in the IAH and non-IAH groups

\begin{tabular}{|c|c|c|c|c|c|}
\hline & $\begin{array}{l}\text { Total patients(n } \\
=100)\end{array}$ & $\begin{array}{l}\text { IAH group } \\
(n=50)\end{array}$ & $\begin{array}{l}\text { Non-IAH group } \\
(n=50)\end{array}$ & $\mathrm{T} / \mathrm{X} 2$ & $p$ \\
\hline Age & $45.59 \pm 11.4$ & $45.28 \pm 12.27$ & $45.90 \pm 10.58$ & 0.271 & 0.787 \\
\hline Males,n(\%) & $55(55 \%)$ & $29(58 \%)$ & $26(52 \%)$ & 0.634 & 0.547 \\
\hline \multicolumn{6}{|l|}{$\begin{array}{l}\text { Admission } \\
\text { reasons }\end{array}$} \\
\hline medical & $30(30 \%)$ & $10(20 \%)$ & $20(40 \%)$ & 9.802 & $0.007^{*}$ \\
\hline surgical & $43(43 \%)$ & $20(40 \%)$ & $23(46 \%)$ & & \\
\hline trauma & $27(27 \%)$ & $20(40 \%)$ & $7(14 \%)$ & & \\
\hline BMI & $25.28 \pm 2.56$ & $25.63 \pm 2.47$ & $24.94 \pm 2.62$ & -1.360 & 0.176 \\
\hline APACHE II & $18.39 \pm 4.72$ & $19.00 \pm 3.63$ & $17.77 \pm 5.57$ & -1.310 & 0.195 \\
\hline SOFA & $5.30 \pm 1.61$ & $5.30 \pm 1.43$ & $5.30 \pm 1.79$ & 0.000 & 1.000 \\
\hline $\begin{array}{l}\text { ISS } \\
(n=27)\end{array}$ & $\begin{array}{l}23.19 \pm 6.98 \\
(n=27)\end{array}$ & $\begin{array}{l}24.70 \pm 6.42(n= \\
20)\end{array}$ & $\begin{array}{l}18.86 \pm 7.17 \\
(n=7)\end{array}$ & -2.010 & 0.055 \\
\hline РСТ & $5.16(3.41,7.70)$ & $7.089(4.07,8.74)$ & $4.79(2.97,5.43)$ & -3.733 & $0.0002^{*}$ \\
\hline CRP & $10.47(7.20,13.59)$ & $9.58(7.13,13.50)$ & $11.07(7.41,13.92)$ & 1.031 & 0.305 \\
\hline LAC & $3.85(1.92,5.39)$ & $3.64(2.36,5.56)$ & $3.92(1.63,5.25)$ & -0.534 & 0.594 \\
\hline Sepsis & $75(75 \%)$ & $37(74 \%)$ & $38(76 \%)$ & 0.053 & 0.817 \\
\hline IVP(day1) & $12.79(6.13,18.99)$ & $18.99(17.52,20.77)$ & $6.14(3.48,8.70)$ & -8.614 & $\llbracket 0.0001^{*}$ \\
\hline IVP(mean) & $11.49(6.66,19.43)$ & $19.43(16.87,22.25)$ & $6.66(2.74,9.08)$ & -8.538 & $\nabla 0.0001^{*}$ \\
\hline AWT(day1) & $2.75 \pm 0.38$ & $2.89 \pm 0.32$ & $2.45 \pm 0.29$ & -7.330 & 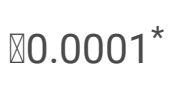 \\
\hline AWT(mean) & $2.75 \pm 0.47$ & $2.82 \pm 0.46$ & $2.43 \pm 0.39$ & -4.870 & $\llbracket 0.0001^{*}$ \\
\hline $\begin{array}{l}\text { Death } \\
\text { within } 28 \\
\text { days }\end{array}$ & $26(52 \%)$ & $18(36 \%)$ & $8(16 \%)$ & 5.198 & $0.023^{*}$ \\
\hline
\end{tabular}

Note: *pख0.05.

Abbreviations: BMI,Body mass index;ISS injury severity score $\llbracket A P A C H E \llbracket A c u t e$ Physiology, Age, Chronic Health Evaluation $\square S O F A \rrbracket$ sequential organ failure $\triangle P C T \square$ procalcitonin $\square L a c \square l a c t i c$ acid $\square C R P \square C$-reactive

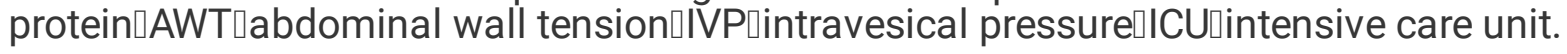




\begin{tabular}{|c|c|c|c|c|c|}
\hline & $\begin{array}{l}\text { Total patients(n } \\
=100)\end{array}$ & $\begin{array}{l}\text { IAH group } \\
(\mathrm{n}=50)\end{array}$ & $\begin{array}{l}\text { Non-IAH group } \\
(\mathrm{n}=50)\end{array}$ & $\mathrm{T} / \mathrm{X} 2$ & $p$ \\
\hline $\begin{array}{l}\text { Death } \\
\text { within } 90 \\
\text { days }\end{array}$ & $29(58 \%)$ & $20(40 \%)$ & $9(18 \%)$ & 5.877 & $0.015^{\star}$ \\
\hline $\begin{array}{l}\text { ICU stay } \\
\text { time }\end{array}$ & $7.74 \pm 3.61$ & $7.48 \pm 3.88$ & $6.01 \pm 3.14$ & -2.380 & $0.019^{*}$ \\
\hline $\begin{array}{l}\text { Total stay } \\
\text { time }\end{array}$ & $15.57 \pm 4.92$ & $15.35 \pm 5.26$ & $13.10 \pm 4.24$ & -2.660 & $0.009^{*}$ \\
\hline \multicolumn{6}{|c|}{ Note: *pه0.05. } \\
\hline \multicolumn{6}{|c|}{ 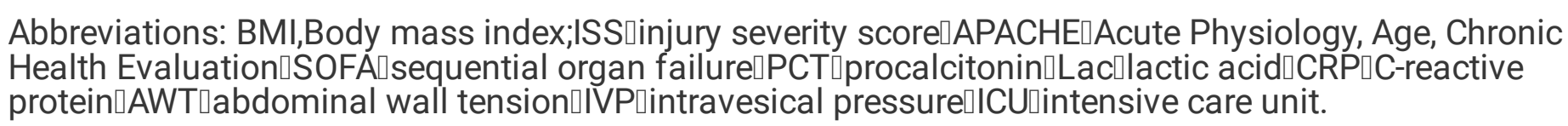 } \\
\hline
\end{tabular}

\subsection{Risk factors for IAH in the IAH and non-IAH groups}

In the IAH group, there were 20 trauma patients (40\%) and 13 intestinal obstruction patients (26\%) versus 7 trauma patients (14\%) and 4 intestinal obstruction ( $8 \%$ ) in the non-IAH group, with significant differences ( $\mathrm{p}$ $<0.05)$. In the non-IAH group, there were 12 patients (24\%) with laparotomy and 17 patients (34\%) with hepatic insufficiency versus 3 patients $(6 \%)$ with laparotomy and 6 patients $(12 \%)$ with hepatic insufficiency in the IAH group. There was no significant difference in other risk factors between the two groups (Table 2). 
Table 2

$\mathrm{IAH}$ risk factors for patients in the IAH and non-IAH groups

\begin{tabular}{|c|c|c|c|c|c|}
\hline & Total patients $(n=100)$ & $\begin{array}{l}\text { IAH group } \\
(n=50)\end{array}$ & $\begin{array}{l}\text { Non-IAH group } \\
(n=50)\end{array}$ & $\mathrm{T} / \mathrm{X} 2$ & $p$ \\
\hline \multicolumn{6}{|c|}{ Decreased abdominal wall tension(n,\%) } \\
\hline ventilation & $24(24 \%)$ & $11(22 \%)$ & $13(26 \%)$ & 0.219 & 0.640 \\
\hline laparotomy & $15(15 \%)$ & $3(6 \%)$ & $12(24 \%)$ & 6.353 & $0.012^{*}$ \\
\hline trauma & $27(27 \%)$ & $20(40 \%)$ & $7(14 \%)$ & 7.602 & $0.006^{*}$ \\
\hline FAT & $55(55 \%)$ & $31(62 \%)$ & $24(48 \%)$ & 1.980 & 0.159 \\
\hline \multicolumn{6}{|c|}{ Increased intestinal contents(n,\%) } \\
\hline retention & $21(21 \%)$ & $13(26 \%)$ & $8(16 \%)$ & 1.507 & 0.220 \\
\hline ileus & $17(17 \%)$ & $13(26 \%)$ & $4(8 \%)$ & 5.741 & $0.017^{\star}$ \\
\hline \multicolumn{6}{|c|}{ Increased abdominal content(n,\%) } \\
\hline bleeding & $17(17 \%)$ & $8(16 \%)$ & $9(18 \%)$ & 0.071 & 0.790 \\
\hline Child-Pugh & $23(23 \%)$ & $6(12 \%)$ & $17(34 \%)$ & 6.832 & $0.009^{*}$ \\
\hline cirrhosis & $10(10 \%)$ & $4(8 \%)$ & $6(12 \%)$ & 0.444 & 0.505 \\
\hline ascites & $24(24 \%)$ & $13(26 \%)$ & $11(22 \%)$ & 0.219 & 0.640 \\
\hline \multicolumn{6}{|c|}{ Capillary leakage or related fluid resuscitation $(n, \%)$} \\
\hline Acidosis & $8(8 \%)$ & $3(6 \%)$ & $5(10 \%)$ & 0.544 & 0.461 \\
\hline Hypotension & $15(15 \%)$ & $3(6 \%)$ & $12(24 \%)$ & 6.353 & $0.012^{*}$ \\
\hline Hypothermia & $9(9 \%)$ & $3(6 \%)$ & $6(12 \%)$ & 1.099 & 0.295 \\
\hline coagulation & $8(8 \%)$ & $5(10 \%)$ & $3(6 \%)$ & 0.544 & 0.461 \\
\hline resuscitation & $29(29 \%)$ & $15(30 \%)$ & $14(28 \%)$ & 0.049 & 0.826 \\
\hline oliguria & $27(27 \%)$ & $13(26 \%)$ & $14(28 \%)$ & 0.051 & 0.822 \\
\hline sepsis & $25(25 \%)$ & $13(26 \%)$ & $12(24 \%)$ & 0.053 & 0.817 \\
\hline transfusion & $8(8 \%)$ & $2(4 \%)$ & $6(12 \%)$ & 2.174 & 0.140 \\
\hline
\end{tabular}

3.3 Correlation analysis of IVP and AWT of the total patients on days 1-7 after entering the ICU 
The average IVP of the total patients on days $1-7$ after entering the ICU was $12.78(6.14,18.99), 11.79$ $(6.23,19.25), 10.92(6.18,19.35), 11.24(6.10,19.26), 11.90(6.57,19.84), 12.37(6.39,19.58)$, and 12.07 $(6.08,19.60)$, respectively. The 7-day average IVP was $11.49(6.66,19.43) \mathrm{mmHg}$. The AWT on days 1-7 after entering the ICU was $2.75 \pm 0.38,2.77 \pm 0.43,2.73 \pm 0.49,2.76 \pm 0.50,2.74 \pm 0.55,2.74 \pm 0.60$, and 2.74 \pm 0.67 , respectively, and the 7-day average AWT was $2.75 \pm 0.47 \mathrm{~N} / \mathrm{mm}$, with significant differences $(p<$ 0.0001 ). The polynomial fitting equation of the day 1 was $\mathrm{AWT}_{\text {day } 1}=-2.450 \times 10^{-3} \mathrm{IVP}^{2}+9.695 \times 10^{-2} \mathrm{IVP}+$ 2.046. The polynomial fitting equation of the 7-day average AWT was as follows: $A W T_{\text {mean }}=-2.293 \times 10^{-3}$ IVP $+9.273 \times 10^{-2}$ IVP +2.081 (Table 3 and Fig. 4).

Table 3

Polynomial regression model of IVP, average IVP and AWT of total patients on days 1-7 after entering the ICU

\begin{tabular}{|c|c|c|c|}
\hline Time & IVP(mmHg) & AWT(N/mm) & Polynomial regression model \\
\hline $\begin{array}{l}\text { Day } \\
1\end{array}$ & $12.78(6.14,18.99)$ & $2.75 \pm 0.38$ & $\begin{array}{l}\text { AWT }=-2.450 \times 10^{-3} I V^{2}+9.695 \times 10^{-2} I V P+2.046, r= \\
0.667(p \otimes 0.0001)\end{array}$ \\
\hline $\begin{array}{l}\text { Day } \\
2\end{array}$ & $11.79(6.23,19.25)$ & $2.77 \pm 0.43$ & $\begin{array}{l}\text { AWT }=-1.715 \times 10^{-4} I V P^{2}+7.536 \times 10^{-2} I V P+2.195, r= \\
0.502(p \otimes 0.0001)\end{array}$ \\
\hline $\begin{array}{l}\text { Day } \\
3\end{array}$ & $10.92(6.18,19.35)$ & $2.73 \pm 0.49$ & $\begin{array}{l}\text { AWT }=-2.221 \times 10^{-3} I V P^{2}+8.754 \times 10^{-2} I V P+2.104, r= \\
0.438(p \otimes 0.0001)\end{array}$ \\
\hline $\begin{array}{l}\text { Day } \\
4\end{array}$ & $11.24(6.10,19.26)$ & $2.76 \pm 0.50$ & $\begin{array}{l}\text { AWT }=-2.044 \times 10^{-3} I V P^{2}+8.115 \times 10^{-2} I V P+2.189, r= \\
0.440(p \otimes 0.0001)\end{array}$ \\
\hline $\begin{array}{l}\text { Day } \\
5\end{array}$ & $11.90(6.57,19.84)$ & $2.74 \pm 0.55$ & $\begin{array}{l}\text { AWT }=-1.373 \times 10^{-3} I V P^{2}+6.484 \times 10^{-1} I V P+2.220, r= \\
0.358(p \otimes 0.0001)\end{array}$ \\
\hline $\begin{array}{l}\text { Day } \\
6\end{array}$ & $12.37(6.39,19.58)$ & $2.74 \pm 0.60$ & $\begin{array}{l}\text { AWT }=-1.112 \times 10^{-4} \mathrm{IVP}^{2}+5.970 \times 10^{-2} \mathrm{IVP}+2.247, \mathrm{r}= \\
0.366(\mathrm{p} \otimes 0.0001)\end{array}$ \\
\hline $\begin{array}{l}\text { Day } \\
7\end{array}$ & $12.07(6.08,19.60)$ & $2.74 \pm 0.67$ & $\begin{array}{l}\text { AWT }=-0.182 \times 10^{-3} I V P^{2}+3.780 \times 10^{-2} I V P+2.341, r= \\
0.331(p \otimes 0.0001)\end{array}$ \\
\hline Mean & $11.49(6.66,19.43)$ & $2.75 \pm 0.47$ & $\begin{array}{l}\text { AWT }=-2.293 \times 10^{-3} I V P^{2}+9.273 \times 10^{-2} \mathrm{IVP}+2.081, \mathrm{r}= \\
0.508(\mathrm{p} \otimes 0.0001)\end{array}$ \\
\hline
\end{tabular}

\subsection{Basic and clinical data of patients in different prognosis groups}

There were 26 patients ( 11 males, $42.31 \%$ ) in the nonsurvival group, with an average age of $45.77 \pm 11.13$ years, and 74 patients ( 44 males, $59.46 \%$ ) in the survival group, with an average age of $45.53 \pm 11.57$ years.

In the nonsurvival group, 5 patients (19.23\%) were admitted to the hospital for medical reasons, 14 patients (53.85\%) were admitted to the hospital for surgical reasons, and 7 patients $(26.92 \%)$ were admitted to the 
hospital for trauma. In the survival group, 25 patients (33.78\%) were admitted to the hospital for medical reasons, 29 patients (39.19\%) were admitted to the hospital for surgical reasons, and 20 patients $(27.03 \%)$ were admitted to the hospital for trauma, $p=0.314$.

The APACHE II score $(21.83 \pm 4.88$ points $)$ and lactate $[5.52(2.71,6.72) \mathrm{mmol} / \mathrm{L}]$ in the nonsurvival group were significantly higher than those in the survival group $[17.18 \pm 4.05$ points and $3.29(1.63,4.71) \mathrm{mmol} / \mathrm{L}$, respectively] $(p<0.005)$. The average IVP on day 1 and mean 7 day of the nonsurvival group was 17.91 $(9.84,20.04)$ and $18.70(9.42,21.16) \mathrm{mmHg}$, respectively, higher than that of the survival group [10.14 (4.95, 18.45), $10.21(5.07,18.13) \mathrm{mmHg}, \mathrm{p}<0.05]$ (Table 4). 
Table 4

Basic and clinical data of patients in different prognosis groups

\begin{tabular}{|c|c|c|c|c|c|}
\hline & $\begin{array}{l}\text { Total patients }(\mathrm{n}= \\
\text { 100) }\end{array}$ & $\begin{array}{l}\text { Nonsurvival group(n } \\
=26)\end{array}$ & $\begin{array}{l}\text { Survival group }(n= \\
74)\end{array}$ & $\mathrm{T} / \mathrm{X} 2 / \mathrm{Z}$ & $p$ \\
\hline Age & $45.59 \pm 11.40$ & $45.77 \pm 11.13$ & $45.53 \pm 11.57$ & 0.093 & 0.926 \\
\hline Males,n(\%) & $55(55 \%)$ & $11(42.31 \%)$ & $44(59.46 \%)$ & 2.287 & 0.131 \\
\hline \multicolumn{6}{|c|}{ Admission reasons } \\
\hline Medial & $30(60 \%)$ & $5(19.23 \%)$ & $25(33.78 \%)$ & 2.320 & 0.314 \\
\hline Surgical & $43(86 \%)$ & 14(53.85\%) & $29(39.19 \%)$ & & \\
\hline Trauma & $27(54 \%)$ & $7(26.92 \%)$ & $20(27.03 \%)$ & & \\
\hline BMI & $25.28 \pm 2.56$ & $24.61 \pm 2.51$ & $25.52 \pm 2.55$ & 1.570 & 0.120 \\
\hline APACHE II & $18.39 \pm 4.72$ & $21.83 \pm 4.88$ & $17.18 \pm 4.05$ & -4.770 & $\nabla 0.0001^{\star}$ \\
\hline SOFA & $5.30 \pm 1.61$ & $5.69 \pm 1.89$ & $5.16 \pm 1.49$ & -1.450 & 0.150 \\
\hline \multirow[t]{2}{*}{ ISS(n) } & $23.19 \pm 6.98$ & $22.00 \pm 6.06$ & $23.60 \pm 7.38$ & 0.510 & 0.612 \\
\hline & $(n=27)$ & $(n=7)$ & $(n=20)$ & & \\
\hline РСТ & $5.16(3.41,7.70)$ & $6.65(4.73,8.96)$ & $4.99(3.20,7.29)$ & 1.709 & 0.091 \\
\hline LAC & $10.47(7.20,13.59)$ & $5.52(2.71,6.72)$ & $3.29(1.63,4.71)$ & 2.904 & $0.004^{*}$ \\
\hline CRP & $3.85(1.92,5.39)$ & $13.23(7.77,16.38)$ & $10.30(6.65,12.89)$ & 1.497 & 0.134 \\
\hline IVP(day1) & $12.79(6.13,18.99)$ & $17.91(9.84,20.04)$ & $10.14(4.95,18.45)$ & 2.165 & $0.030^{*}$ \\
\hline IVP(mean) & $11.49(6.66,19.43)$ & $18.70(9.42,21.16)$ & $10.21(5.07,18.13)$ & 2.334 & $0.019^{*}$ \\
\hline AWT(day1) & $2.75 \pm 0.38$ & $2.84 \pm 0.30$ & $2.72 \pm 0.40$ & -1.370 & 0.173 \\
\hline AWT(mean) & $2.75 \pm 0.47$ & $2.82 \pm 0.49$ & $2.72 \pm 0.46$ & -0.950 & 0.343 \\
\hline ICU time & $7.74 \pm 3.61$ & $8.38 \pm 3.73$ & $7.51 \pm 3.56$ & -1.060 & 0.292 \\
\hline total time & $15.57 \pm 4.92$ & $15.96 \pm 6.52$ & $15.43 \pm 4.27$ & -0.470 & 0.640 \\
\hline \multicolumn{6}{|c|}{ Note: *p邓0.05. } \\
\hline $\begin{array}{l}\text { Abbreviatio } \\
\text { Health Eval } \\
\text { protein } \square A W\end{array}$ & $\begin{array}{l}\text { Ml,body mass ir } \\
\text { n\SOFA sequen } \\
\text { dominal wall ter }\end{array}$ & $\begin{array}{l}\text { SDinjury sever } \\
\text { gan failure』PC } \\
\text { VP』intravesica }\end{array}$ & 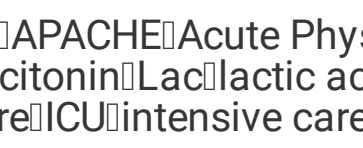 & $\begin{array}{l}\text { ology, A } \\
\text { IवCRP } \square \text { C } \\
\text { init. }\end{array}$ & $\begin{array}{l}\text { Chronic } \\
\text { ictive }\end{array}$ \\
\hline
\end{tabular}

\subsection{Risk factors for 28-day death in different prognostic groups}


In the nonsurvival group, 8 patients (30.77\%) suffered from intestinal obstruction, and 18 IAH patients (69.23\%), which was significantly higher than in the survival group [9 patients $(12.16 \%)$ suffered from intestinal obstruction, and $32 \mathrm{IAH}$ patients (43.24\%), P = 0.03; P = 0.002]. There was no significant difference in other indicators between the two groups (Table 5).

Table 5

Risk factors for death within 28 days in different prognostic groups

\begin{tabular}{|lllll|}
\hline Risk factors & Nonsurvival group( $\mathbf{n}=\mathbf{2 6})$ & Survival group( $\mathbf{n = 7 4 )}$ & T/X2 & $\boldsymbol{p}$ \\
\hline Age $\varangle 65$ & 0 & $4(5.41 \%)$ & 1.464 & 0.226 \\
\hline sepsis & $16(61.54 \%)$ & $59(79.73 \%)$ & 3.396 & 0.065 \\
\hline laparotomy & $5(19.23 \%)$ & $10(13.51 \%)$ & 0.493 & 0.483 \\
\hline ileus & $8(30.77 \%)$ & $9(12.16 \%)$ & 4.721 & $0.030^{*}$ \\
\hline Acidosis & $3(11.54 \%)$ & $5(6.76 \%)$ & 0.598 & 0.440 \\
\hline coagulation & $4(15.38 \%)$ & $4(5.41 \%)$ & 2.603 & 0.107 \\
\hline transfusion(10u/day) & $3(11.54 \%)$ & $5(6.76 \%)$ & 0.598 & 0.440 \\
\hline damage control surgery & $3(11.54 \%)$ & $13(17.57 \%$ & 0.520 & 0.471 \\
\hline IAH & $18(69.23 \%)$ & $32(43.24 \%)$ & 9.600 & $0.002^{*}$ \\
\hline Note: ${ }^{*}$ p $\otimes 0.05$. & & & & \\
\hline
\end{tabular}

\subsection{Logistic regression analysis of 28-day death risk factors for all patients}

Logistic regression analysis showed that the APACHE II score increased the risk of death at 28 days (OR: 1.381; 95\%: 1.139-1.581, $\mathrm{p}=0.0002$ ). $\mathrm{AWT}_{\text {day } 1}$ (AWT 2.73-2.97 N/mm)increased the 28-day mortality risk (OR: 6.834; 95\%: 1.105-42.266, $\mathrm{p}=0.010$ ). There was no significant difference in other indicators (Table 6). 
Table 6

Logistic regression analysis of 28-day death risk factors

\begin{tabular}{|c|c|c|c|c|c|}
\hline Index & OR & $2.5 \%$ & $97.5 \%$ & p & The number of patients $\mathrm{n}(\%)$ \\
\hline APACHE II & 1.381 & 1.139 & 1.581 & $0.0002^{*}$ & 100 \\
\hline SOFA & 1.304 & 0.845 & 2.012 & 0.203 & 100 \\
\hline Sepsis & 1.468 & 0.405 & 5.321 & 0.783 & 75 \\
\hline Lactate & 1.381 & 0.756 & 2.52 & 0.294 & 100 \\
\hline IAH not ACS & 4.776 & 1.128 & 20.220 & 0.209 & 39 \\
\hline ACS & 4.591 & 0.673 & 31.328 & 0.382 & 11 \\
\hline $\begin{array}{l}1 / 4-2 / 4 \mathrm{AWT}_{\text {day } 1} \\
\text { (AWT } 2.54-2.73 \mathrm{~N} / \mathrm{mm})\end{array}$ & 1.906 & 0.289 & 12.564 & 0.960 & 25 \\
\hline $\begin{array}{l}2 / 4-3 / 4 \text { AWT day1 } \\
\text { (AWT 2.73-2.97N/mm) }\end{array}$ & 6.834 & 1.105 & 42.266 & $0.010^{*}$ & 25 \\
\hline $\begin{array}{l}\varangle 3 / 4 \text { AWT day1 } \\
\text { (AWT } 2.97-3.48 \mathrm{~N} / \mathrm{mm} \text { ) }\end{array}$ & 0.845 & 0.117 & 6.115 & 0.170 & 25 \\
\hline \multicolumn{6}{|l|}{ Note: *p囚0.05. } \\
\hline 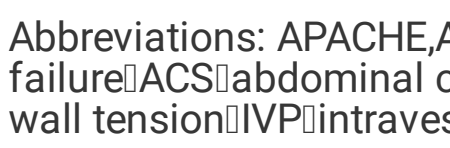 & $\begin{array}{l}\text { Physi } \\
\text { pressu }\end{array}$ & $\begin{array}{l}\text { gy, Age } \\
\text { yndror } \\
\text { ICUIint }\end{array}$ & $\begin{array}{l}\text { Shronic } \\
\text { IAHपin } \\
\text { Isive ca }\end{array}$ & $\begin{array}{l}\text { th Evalu } \\
\text { odomina } \\
\text { it. }\end{array}$ & $\begin{array}{l}\text { n;SOFA } \square \text { sequential organ } \\
\text { ypertension } \square A W T \square \text { abdominal }\end{array}$ \\
\hline
\end{tabular}

\section{Discussion}

Since the concept of AC was proposed in 2014, AC has gradually become an important advancement and research direction in the field of IAH and ACS[8-9]. In 2015, WSACS further revised its name to the Abdominal Compartment Society (www.wsacs.org) with the purpose of ensuring that doctors and researchers fully understand the integrity of the abdominal cavity, the relationship among the organs in the cavity, the functional state between multiple cavities, and the pathophysiological process of disease occurrence and development[2, 15]. The abdominal wall occupies most of the soft border of the abdominal cavity and plays a major role in AC. Therefore, the assessment of AWT is even more important for AC[7-8, 16]. In addition, with the vigorous development of abdominal surgery, technical updates, and a broader understanding of abdominal wall anatomy and physiology in recent years, there is also an urgent need for technology that can evaluate AWT[4, 17-19].

Through the measurement of AWT in critically ill patients and an epidemiological indicator analysis in patients with abdominal hypertension, we found that patients with abdominal hypertension have higher AWT, and there is a nonlinear correlation between AWT and IVP. Our research obtained similar results in 
AWT measurement compared with previous studies, and there were also some new findings. The earliest description of the invasive measurement method of AWT was published in a study of abdominal surgery. Bertram et al. $[11,19]$ used a tensiometer to perform AWT measurements on abdominal wall incisions, compared the operative complications such as the recurrence rate of incisional hernia in the measurement group and the nonmeasurement group, and found that the incision tension level was between $1.5 \mathrm{kP}$ and $3.5 \mathrm{kP}$. By controlling the incision tension below $1.5 \mathrm{kP}$, the incisional hernia recurrence rate could be reduced from $44-22 \%$, and the patch usage rate was reduced from $6-2 \%$. A correct understanding of AWT can help surgeons perform surgical operations better and reduce surgical complications. In 2013, WSACS also focused on the important role of AWT in AC and described the method of calculating AWT based on La Place's law [9, 20-21]. In 2008, Ramshorst et al. [22] first performed AWT measurements in two cadavers. In the preliminary experiment, a linear regression equation was used to analyze the correlation between AWT and IAP, and a good association was found at the 7 measurement points of the abdominal wall. In 2011, Ramshorst et al. [23] conducted AWT measurement experiments on cadavers and healthy volunteers and found that AWT and IAP were linearly correlated, with the highest correlation in the upper abdomen. In 2015, Chen et al. [14] conducted AWT measurements on critically ill patients and found that the AWT index was between 0.5 and $3.5 \mathrm{~N} / \mathrm{mm}$, and AWT and IVP were linearly correlated with good correlation. At the same time, the author also found that breathing, body position and body mass index (BMI) may affect AWT.

A commonly used method for data correlation analyses in medical research is the linear regression equation. The limitation of linear regression is that it can only be applied to data with linear relationships. However, in clinical practice, many data have nonlinear relationships. Although linear regression can also be used to fit nonlinear regression, the effect will be very poor[24]. Considering the complexity of the abdominal wall structure and the possible nonlinear relationship between AWT and IVP, we used a polynomial regression method to analyze the correlation between AWT and IVP. We divided the IVP into 5 different pressure areas, performed clustering to obtain the cluster centers, and then used polynomial regression and a quadratic function for fitting. The fitting function showed that the area where the IVP is below $15 \mathrm{mmHg}$ is close to a linear correlation, and the area above $15 \mathrm{mmHg}$ is similar to a horizontal parabolic relationship. We speculate that this result is related to abdominal compliance. AWT plays a major role in AC, and the characteristics of AWT at different pressure stages also play a decisive role in $\mathrm{AC}[25]$. In 2008, Mulier et al. [7, 9] studied the relationship between intra-abdominal pressure and inflation volume under laparoscopic pneumoperitoneum and used a digital model to calculate the relationship between intraabdominal pressure and volume. The study found that the relationship between IAV and IAP is not linear. It can be divided into three stages: shaping, stretching and pressurizing. The slope of these three stages is a curve that starts to flatten and increases rapidly in the later stage. This performance can be understood as the difference in the elasticity of the abdominal wall at different pressure stages. When a certain critical value is reached, the elasticity no longer increases, which may lead to a rapid increase in abdominal pressure by a slight volume change [18]. Therefore, our research results can better reflect the true changes in the elasticity of the abdominal wall at different pressure levels. The current conventional method for measuring intra-abdominal pressure is measuring the transvesical pressure. In 2018, Abdulla et al.[26] compared the correlation between intra-abdominal pressure and intravesical pressure in patients undergoing laparoscopic cholecystectomy under general anesthesia and found that IVP and IAP have a 
linear correlation, where the correlation is good when $<12 \mathrm{mmHg}$ and the correlation is relatively poor when $>12 \mathrm{mmHg}$. In addition, in some clinical situations, such as pelvic fractures, pelvic hematomas, peritoneal adhesions, and neurogenic bladder, the intravesical pressure cannot be measured[26-27]. In the two situations above, the patient's AWT can be measured, and the results of IAP can be calculated using our polynomial regression model to accurately assess IAP, which has potential clinical application value.

Our study found that patients with abdominal hypertension had higher 28-day and 90-day mortality. The regression analysis showed that the APACHE II score increased the 28-day mortality, which is similar to previous research results. In 2005, a multicenter epidemiological study conducted by Malbrin et al. [28] analyzed the relationship between the first day of admission and new emergence during hospitalization and the relationship between average IAH and poor prognosis. Studies have shown that IAH on the first day of admission is related to organ dysfunction during ICU hospitalization. The average IAP during hospitalization is not an independent risk factor for death, and newly appearing IAH during hospitalization is a risk factor for death. The results of the 2019 IROI study also showed that new IAH during hospitalization can increase 28-day and 90-day mortality, and the APACHE II score on day 1 is an independent risk factor for death[29]. According to a large number of animal and clinical studies in the past, abdominal hypertension directly or indirectly affects the abdominal cavity or organs outside the abdominal cavity, causing multiple organ dysfunction, which is the direct cause of hospital death[30-32]. ACS is defined as IAP > $20 \mathrm{mmHg}$ with newly emerging organ dysfunction[1, 3, 33-34]. The more important effect of IAH is the dynamic changes in IAP caused by IAV. Therefore, the WSACS has introduced the concept of $A C$ in recent years, emphasizing the role of compliance in the diagnosis and treatment of $\operatorname{IAH}[1,2,7,8]$. We adopted a noninvasive, portable and simple AWT measurement method that has potential value in the early diagnosis and treatment of emerging IAHs.

Our research also found that an AWT of 2.73-2.97 N/mm is a risk factor for death for the following reasons: palpation is a traditional examination for the detection of abdominal diseases. Patients with abdominal hypertension and peritonitis can experience an increase in AWT, but routine examinations are only preliminary judgments and cannot quantitatively and qualitatively diagnose AWT[13, 32, 35]. AWT can reflect not only the degree of stretch but also the condition of abdominal cavity infection. The PCT index in the abdominal hypertension group was higher, which may have led to a higher rate of abdominal infection in patients with high AWT and therefore a higher mortality rate. Second, according to the previous AWT fitting curve, AWT $2.73-2.97 \mathrm{~N} / \mathrm{mm}$ is at the peak of the fitting curve, which is the stage of the highest elastic tension of the abdominal wall; thus, we speculate that at this stage of AWT, the abdominal pressure may be at the point of the cutoff value and that the internal organs of the abdominal cavity are most severely damaged by pressure. This speculation needs to be verified in future experiments. We also hope to quantitatively measure AWT to further understand the structural characteristics of the abdominal wall and provide specific reference materials for the diagnosis and treatment of celiac disease.

Limitations: This study enrolled a small number of patients and required large-sample, multicenter clinical trials and related clinical studies of AWT under different physiological or disease states.

\section{Conclusion}


There was a curve correlation between AWT and IVP in critically ill patients. The polynomial regression model helped us understand the relationship between AWT and IVP. High AWT in critically ill patients indicates poor prognosis.

\section{Declarations}

Funding: This work is supported by the Project: Clinical Technology Innovation and Cultivation Project of Army Medical University (Project No.: cx2019js109); General Project of Chongqing Special Project of Technology Innovation and Application Development (Research on Abdominal Wall Tension Measurement Method Establishment and Clinical Application『cstc2019jscx-msxmx0240).

\section{Ethics approval: This study was approved by our institution review board.}

Conflicts of interests: The authors declare that they have no conflict of interests to declare.

Contributions: $\mathrm{CZ}$ and DCZ collected the data. DL and DPJ participated in the design of the study. HPL and ZGW participated in the design of the study and revised the manuscript. LYZ conceived of the studv, and participated in its design and coordination and helped to revised the manuscript. HT collected the data and wrote the first draft of the manuscript. $X Y H$ and $Y L$ performed the statistical analvsis. YLW participated in the design of the study. All authors read and approved the final manuscript.

\section{Acknowledgment: None.}

Consent for publication: Not applicable.

Availability of data and materials: The datasets generated and analyzed during the current study are available from the corresponding author on reasonable request.

\section{References}

1. Sartelli M, Catena F, Abu-Zidan FM, Ansaloni L, Biffl WL, Boermeester MA, et al. Management of intraabdominal infections: recommendations by the WSES 2016 consensus conference. World J Emerg Surg 2017; 12 22. doi: 10.1186/s13017-017-0132-7.

2. Kirkpatrick AW, Sugrue M, McKee JL, Pereira BM, Roberts DJ, De Waele JJ, et al. Update from the Abdominal Compartment Society (WSACS) on intra-abdominal hypertension and abdominal compartment syndrome: past, present, and future beyond Banff 2017. Anaesthesiol Intensive Ther. 2017;49(2):83-7. doi:10.5603/AIT.a2017.0019.

3. Kirkpatrick AW, Roberts DJ, De Waele J, Jaeschke R, Malbrain ML, De Keulenaer B, et al. Intraabdominal hypertension and the abdominal compartment syndrome: updated consensus definitions and clinical practice guidelines from the World Society of the Abdominal Compartment Syndrome. Intensive Care Med. 2013;39(7):1190-206. doi:10.1007/s00134-013-2906-z. 
4. Jensen KK, Kjaer M, Jorgensen LN. Abdominal muscle function and incisional hernia: a systematic review. Hernia. 2014;18(4):481-6. doi:10.1007/s10029-014-1242-8.

5. Kirkpatrick AW, Roberts DJ, Jaeschke R, De Waele JJ, De Keulenaer BL, Duchesne J, et al. Methodological background and strategy for the 2012-2013 updated consensus definitions and clinical practice guidelines from the abdominal compartment society. Anaesthesiol Intensive Ther. 2015. doi:10.5603/AIT.a2015.0081. 47 Spec No s63-77.

6. Malbrain ML, Cheatham ML, Kirkpatrick A, Sugrue M, Parr M, De Waele J, et al. Results from the International Conference of Experts on Intra-abdominal Hypertension and Abdominal Compartment Syndrome. I. Definitions. Intensive Care Med 2006; 32 (11): 1722-1732. doi: 10.1007/s00134-0060349-5.

7. Malbrain ML, Roberts DJ, De Laet I, De Waele JJ, Sugrue M, Schachtrupp A, et al. The role of abdominal compliance, the neglected parameter in critically ill patients - a consensus review of 16 . Part 1: definitions and pathophysiology. Anaesthesiol Intensive Ther. 2014;46(5):392-405. doi:10.5603/AIT.2014.0062.

8. Blaser AR, Bjorck M, De Keulenaer B, Regli A. Abdominal compliance: A bench-to-bedside review. J Trauma Acute Care Surg. 2015;78(5):1044-53. doi:10.1097/TA.0000000000000616.

9. Malbrain ML, De Laet I, De Waele JJ, Sugrue M, Schachtrupp A, Duchesne J, et al. The role of abdominal compliance, the neglected parameter in critically ill patients - a consensus review of 16. Part 2: measurement techniques and management recommendations. Anaesthesiol Intensive Ther. 2014;46(5):406-32. doi:10.5603/AIT.2014.0063.

10. Feng MP, Baucom RB, Broman KK, Harris DA, Holzman MD, Huang LC, et al. Early repair of ventral incisional hernia may improve quality of life after surgery for abdominal malignancy: a prospective observational cohort study. Hernia. 2019;23(1):81-90. doi:10.1007/s10029-018-1863-4.

11. Bilezikian JA, Faulkner JD, Fox SS, Hooks WBt, Hope WW. Clinical Application of the Measurement of Abdominal Wall Tension in Hernia Repair. Surg Technol Int. 2019;35:129-34.

12. Brown SH. Mechanically relevant consequences of the composite laminate-like design of the abdominal wall muscles and connective tissues. Med Eng Phys. 2012;34(4):521-3. doi:10.1016/j.medengphy.2011.11.008.

13. Reuben A. Examination of the abdomen. Clin Liver Dis (Hoboken). 2016;7(6):143-50. doi:10.1002/cld.556.

14. Chen YZ, Yan SY, Chen YQ, Zhuang YG, Wei Z, Zhou SQ, et al. Noninvasive monitoring of intraabdominal pressure by measuring abdominal wall tension. World J Emerg Med. 2015;6(2):137-41. doi:10.5847/wjem.j.1920-8642.2015.02.009.

15. Malbrain ML, Roberts DJ, Sugrue M, De Keulenaer BL, Ivatury R, Pelosi P, et al. The polycompartment syndrome: a concise state-of-the-art review. Anaesthesiol Intensive Ther. 2014;46(5):433-50. doi:10.5603/AIT.2014.0064.

16. Tayebi S, Gutierrez A, Mohout I, Smets E, Wise R, Stiens J, et al. A concise overview of non-invasive intra-abdominal pressure measurement techniques: from bench to bedside. J Clin Monit Comput. 2020. doi:10.1007/s10877-020-00561-4. 
17. Rajasurya V, Surani S. Abdominal compartment syndrome: Often overlooked conditions in medical intensive care units. World J Gastroenterol. 2020;26(3):266-78. doi:10.3748/wjg.v26.i3.266.

18. Kirkpatrick AW, Nickerson D, Roberts DJ, Rosen MJ, McBeth PB, Petro CC, et al. Intra-Abdominal Hypertension and Abdominal Compartment Syndrome after Abdominal Wall Reconstruction: Quaternary Syndromes? Scand J Surg. 2017;106(2):97-106. doi:10.1177/1457496916660036.

19. Deeken CR, Lake SP. Mechanical properties of the abdominal wall and biomaterials utilized for hernia repair. J Mech Behav Biomed Mater. 2017;74:411-27. doi:10.1016/j.jmbbm.2017.05.008.

20. Havens JM, Soybel DI. Assessment of intra-abdominal pressure by measurement of abdominal wall tension. J Surg Res. 2011;166(1):70-2. doi:10.1016/j.jss.2010.03.010.

21. Basford JR. The Law of Laplace and its relevance to contemporary medicine and rehabilitation. Arch Phys Med Rehabil. 2002;83(8):1165-70. doi:10.1053/apmr.2002.33985.

22. van Ramshorst GH, Lange JF, Goossens RH, Agudelo NL, Kleinrensink GJ, Verwaal M, et al. Noninvasive measurement of intra-abdominal pressure: a preliminary study. Physiol Meas. 2008;29(8):N41-7. doi:10.1088/0967-3334/29/8/N01.

23. van Ramshorst GH, Salih M, Hop WC, van Waes OJ, Kleinrensink GJ, Goossens RH, et al. Noninvasive assessment of intra-abdominal pressure by measurement of abdominal wall tension. J Surg Res. 2011;171(1):240-4. doi:10.1016/j.jss.2010.02.007.

24. Cheng CL, Tsai JR, Schneeweiss H. Polynomial regression with heteroscedastic measurement errors in both axes: Estimation and hypothesis testing. Stat Methods Med Res. 2019;28(9):2681-96. doi:10.1177/0962280218782715.

25. Mulier JP, Dillemans B, Van Cauwenberge S. Impact of the patient's body position on the intraabdominal workspace during laparoscopic surgery. Surg Endosc. 2010;24(6):1398-402. doi:10.1007/s00464-009-0785-8.

26. Al-Abassi AA, Al Saadi AS, Ahmed F. Is intra-bladder pressure measurement a reliable indicator for raised intra-abdominal pressure? A prospective comparative study. BMC Anesthesiol. 2018;18(1):69. doi:10.1186/s12871-018-0539-z.

27. Malbrain ML. Different techniques to measure intra-abdominal pressure (IAP): time for a critical reappraisal. Intensive Care Med. 2004;30(3):357-71. doi:10.1007/s00134-003-2107-2.

28. Malbrain ML, Chiumello D, Pelosi P, Bihari D, Innes R, Ranieri VM, et al. Incidence and prognosis of intraabdominal hypertension in a mixed population of critically ill patients: a multiple-center epidemiological study. Crit Care Med. 2005;33(2):315-22. doi:10.1097/01.ccm.0000153408.09806.1b.

29. Reintam Blaser A, Regli A, De Keulenaer B, Kimball EJ, Starkopf L, Davis WA, et al. Incidence, Risk Factors, and Outcomes of Intra-Abdominal Hypertension in Critically III Patients-A Prospective Multicenter Study (IROI Study). Crit Care Med. 2019;47(4):535-42. doi:10.1097/CCM.0000000000003623.

30. Pereira BM. Abdominal compartment syndrome and intra-abdominal hypertension. Curr Opin Crit Care. 2019;25(6):688-96. doi:10.1097/MCC.0000000000000665. 
31. Maluso P, Olson J, Sarani B. Abdominal Compartment Hypertension and Abdominal Compartment Syndrome. Crit Care Clin. 2016;32(2):213-22. doi:10.1016/j.ccc.2015.12.001.

32. Reintam Blaser A, Starkopf J, Malbrain ML. Abdominal signs and symptoms in intensive care patients. Anaesthesiol Intensive Ther. 2015;47(4):379-87. doi:10.5603/AIT.a2015.0022.

33. Malbrain ML, Chiumello D, Cesana BM, Reintam Blaser A, Starkopf J, Sugrue M, et al. A systematic review and individual patient data meta-analysis on intra-abdominal hypertension in critically ill patients: the wake-up project. World initiative on Abdominal Hypertension Epidemiology, a Unifying Project (WAKE-Up!). Minerva Anestesiol. 2014;80(3):293-306.

34. De Waele JJ, De Laet I, Kirkpatrick AW, Hoste E. Intra-abdominal Hypertension and Abdominal Compartment Syndrome. Am J Kidney Dis. 2011;57(1):159-69. doi:10.1053/j.ajkd.2010.08.034.

35. Bilal M, Voin V, Topale N, Iwanaga J, Loukas M, Tubbs RS. The Clinical anatomy of the physical examination of the abdomen: A comprehensive review. Clin Anat. 2017;30(3):352-6. doi:10.1002/ca.22832.

\section{Figures}

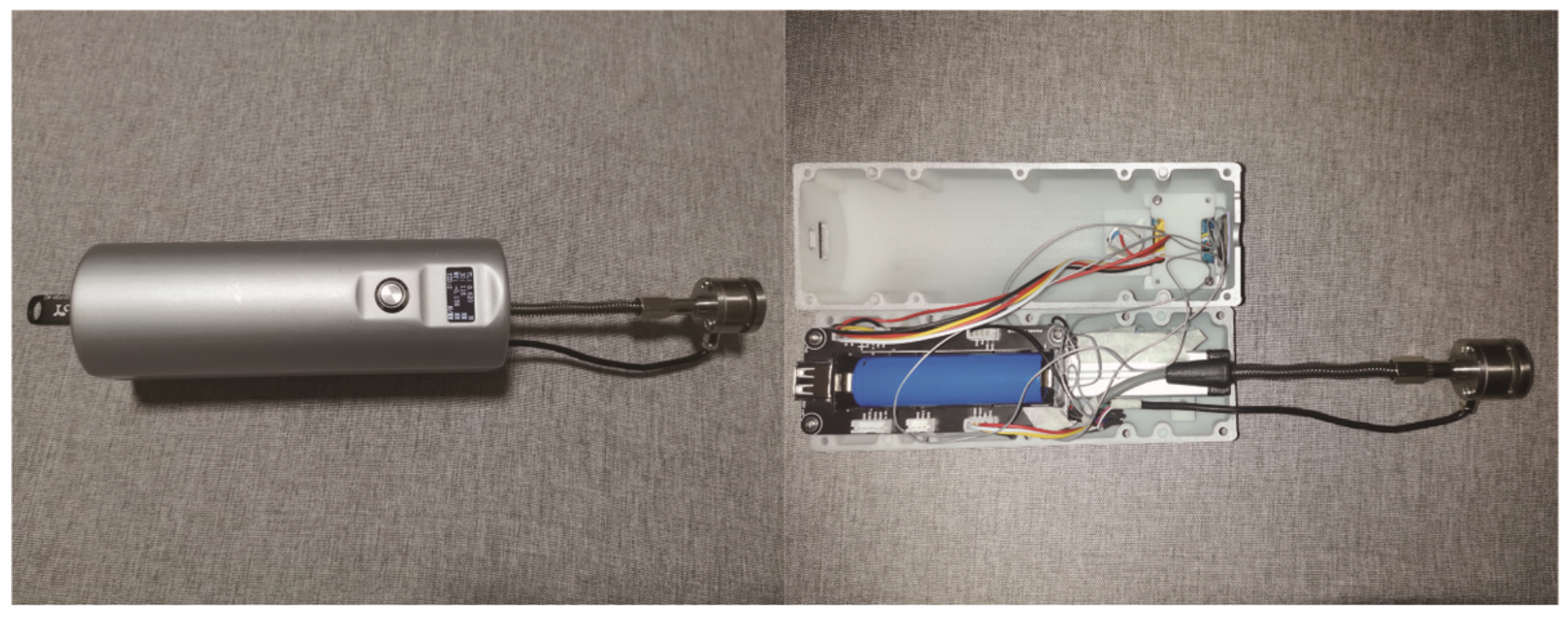

Figure 1

Appearance of AWT measuring equipment 


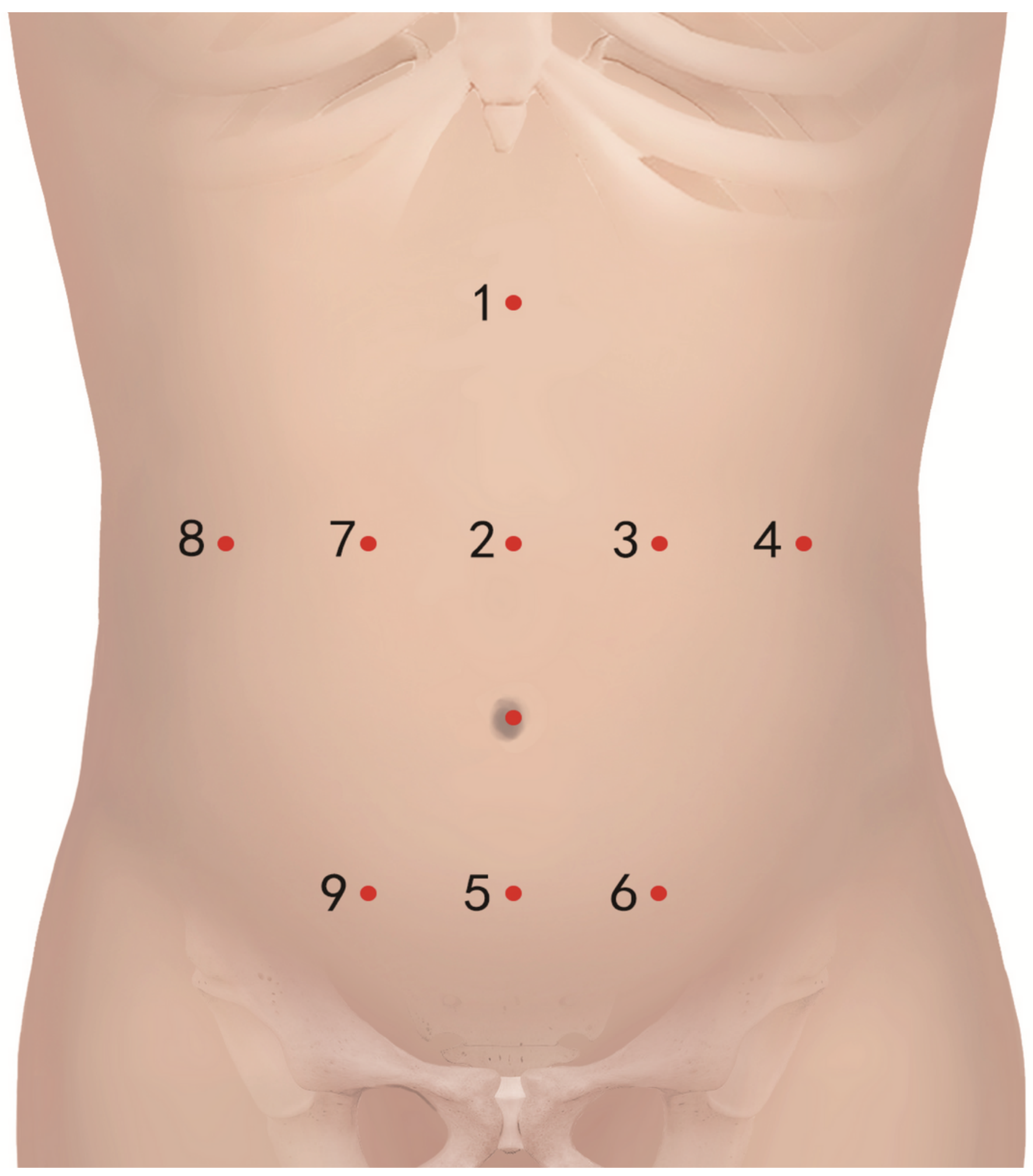

\section{Figure 2}

Body surface location of 9 points on the abdominal wall Notes: Point 1: $5 \mathrm{~cm}$ below the xiphoid process Point 6: $5 \mathrm{~cm}$ to the left of Point 5 Point 2: $5 \mathrm{~cm}$ above the belly button Point 7: $5 \mathrm{~cm}$ to the right of Point 2 Point 3: $5 \mathrm{~cm}$ to the left of Point 2 Point 8: $10 \mathrm{~cm}$ to the right of Point 2 Point 4: $10 \mathrm{~cm}$ to the left of Point 2 Point 9: $5 \mathrm{~cm}$ to the right of Point 5 Point $5: 5 \mathrm{~cm}$ above the symphysis pubis 


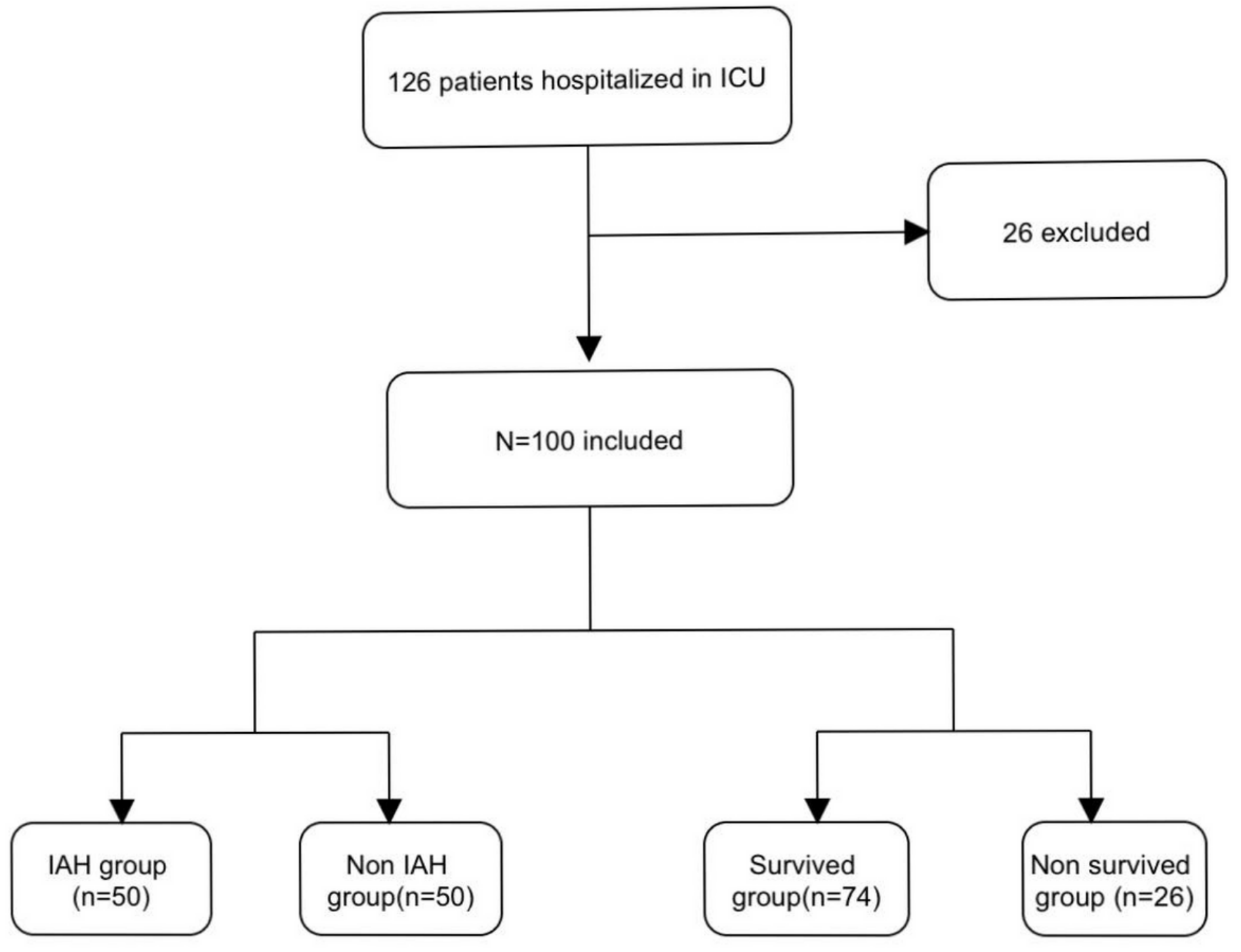

Figure 3

Research flow chart Notes: Abbreviations: AWT, abdominal wall tension; IVP, intravesical pressure; 


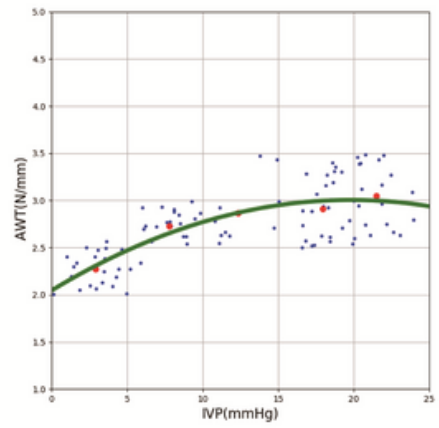

Day 1

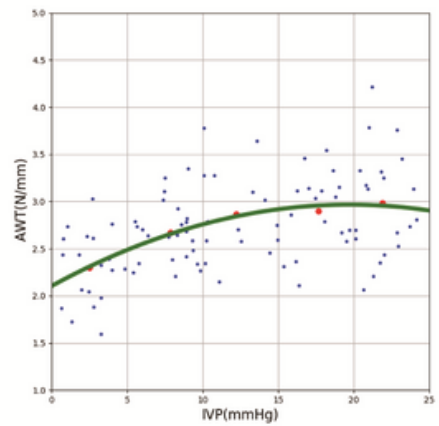

Day 3

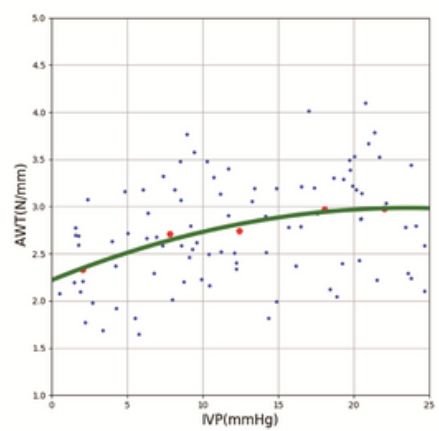

Day 5

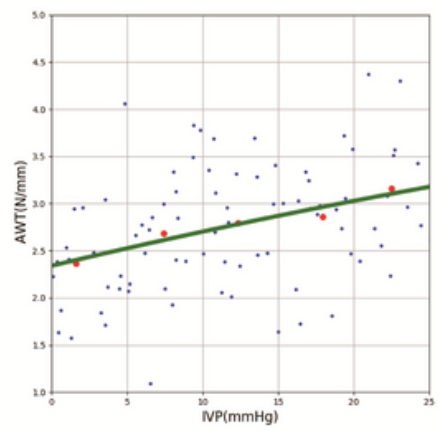

Day 7

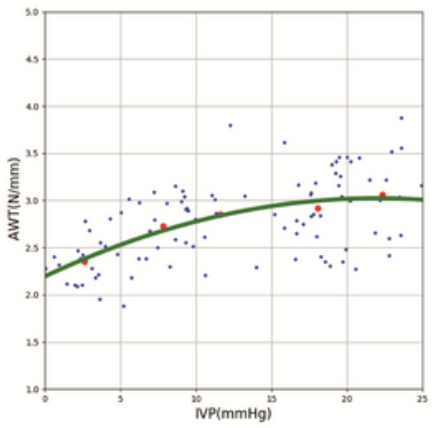

Day 2

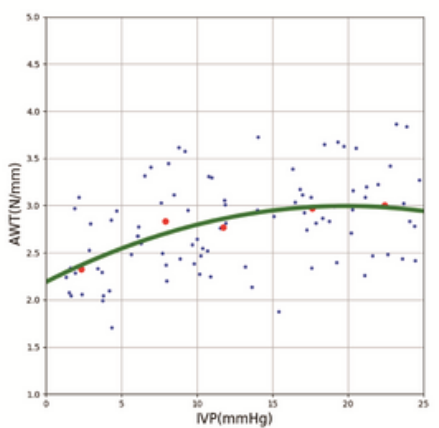

Day 4

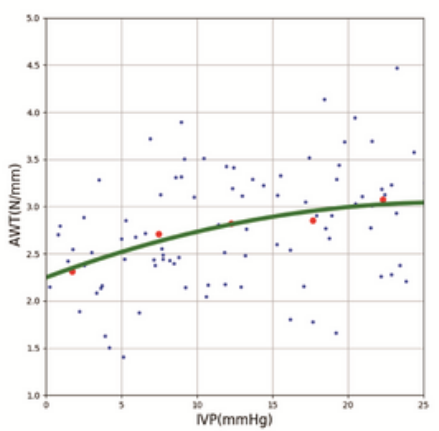

Day 6

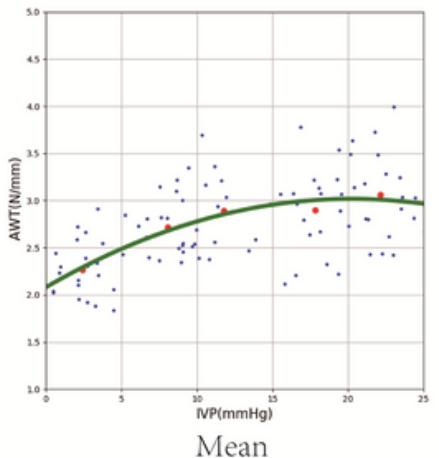

\section{Figure 4}

Polynomial regression curves of IVP, average IVP and AWT of total patients on days 1-7 after entering the ICU Notes $₫$ Red points: cluster points; Green lines: fitted curves. 